\title{
Therapeutic abortion and Chlamydia trachomatis infection
}

\author{
ERIK QVIGSTAD,* KJELL SKAUG,† FRIDTJOF JERVE,* INGER S S VIK,† \\ AND JAN C ULSTRUP† \\ From the *Department of Obstetrics and Gynaecology, and the +Microbiological Laboratory, Ullevaal \\ Hospital, Oslo, Norway
}

SUMMARY Chlamydia trachomatis was isolated from the cervix of 30 of $218(13 \cdot 8 \%)$ women admitted for legal termination of pregnancy. During the first two weeks after the abortion seven of the $30(23 \cdot 3 \%)$ patients developed pelvic inflammatory disease. Four of these had serological evidence of recent active chlamydial infection. Thus, routine examination of patients for genital $\infty$ chlamydial infection before termination of pregnancy is recommended.

\section{Introduction}

The presence of Chlamydia trachomatis in the cervix is a frequent causal factor in the epidemiology of pelvic inflammatory disease (PID). ${ }^{1-4}$ One episode of PID may result in tubal dysfunction; tubal patency is rapidly impaired by recurrent infections and may later cause infertility. ${ }^{5}$ PID due to $C$ trachomatis may also occur without subjective symptoms. ${ }^{3}$

PID is a major complication after therapeutic abortion; the readmission rate in our hospital is about $4 \%$, pelvic infections and retained products being the main causes. ${ }^{6}$

The aim of this study was to record the incidence of $C$ trachomatis infections among patients admitted for legal abortion and to follow those harbouring chlamydia, particularly those in whom it caused postoperative infections.

\section{Patients and methods}

\section{STUDY POPULATION}

Two hundred and eighteen women admitted consecutively for termination of pregnancy in the first trimester in 1980 were included in the study. Abortion was carried out by dilatation and vacuum aspiration in all patients.

The diagnosis of PID was made on the clinical grounds of pelvic pain, adnexal masses, increased erythrocyte sedimentation rate, and fever. The patients who developed acute salpingitis were treated with doxycycline.

Patients who harboured $C$ trachomatis were recalled for follow up about three months after the abortion.

Address for reprints: Dr E Qvigstad, Department of Obstetrics anc Gynaecology, Ullevaal Hospital, Oslo 1, Norway

Accepted for publication 19 November 1981
ISOLATION OF C TRACHOMATIS AND

N GONORRHOEAE

Before surgery specimens for culture of $C_{C}^{-}$ t;achomatis and $N$ gonorrhoeae were obtained from $\subseteq$ the cervix and cultured within 24 hours. The $\mathbb{D}$ chlamydial specimens were collected with cotton- $\overrightarrow{0}$ tipped swabs and transported in a sucrose phosphate $\stackrel{\infty}{\sim}$ buffer (2SP). C trachomatis was cultured in cycloheximide-treated McCoy cells. ${ }^{7}$

Specimens for culture of $N$ gonorrhoeae were collected with charcoal-treated cotton-tipped swabs and transported in a modified Stuart medium. $N \frac{\mathcal{D}}{\mathrm{Q}}$ gonorrhoeae was cultured on a modified Thayer- $\varrho$ Martin medium and identified by sugar fermentation $\overline{\vec{O}}$ tests.

\section{SEROLOGY}

Before abortion and at follow-up examination serum samples were examined for chlamydial IgG anti-훙 bodies by an enzyme-linked immunosorbent assay 3 . (ELISA). ${ }^{8}$ The ELISA was performed on flat-o̊ bottomed microtitre plates coated with a suspension of partially purified cell-cultured $C$ trachomatis sub-응 type LGV-2 particles. Antibody titres were expressed as the highest reciprocal serum dilution showing at을 least twice the mean absorbance value of a group of negative sera. A titre $>1 / 8$ was defined as a positive $\circ$ result. A four-fold or more rise in titre was regarded $N$ as evidence of actual chlamydial infection.

\section{Results}

CULTURE

Of the 218 patients, $C$ trachomatis was isolated from the cervix in $30(13.8 \%), N$ gonorrhoeae in six $\vec{\Phi}$ $(2 \cdot 8 \%)$, and both $C$ trachomatis and $N$ gonorrhoeae $\frac{}{\mathrm{D}}$ in two. 
Seven of the $30(23 \cdot 3 \%)$ patients harbouring $C$ trachomatis developed PID. All the infections occurred in the first two weeks after the abortion. None of the patients with cervical gonorrhoea developed salpingitis.

\section{FOLLOW UP}

Twenty-one of the 30 chlamydia-positive patients attended for follow up three months after the termination of pregnancy (table). Of the seven patients with pelvic infection, six attended (patients 1-6); four of these had an appreciable rise in chlamydial IgG antibody titre while two had raised but unchanged titres. A further four patients (Nos $7-10)$ had a four-fold or more rise in titre but no clinical evidence of infection.

TABLE Chlamydial IgG antibody titres in paired serum samples from 21 patients harbouring $C$ trachomatis by an enzyme-linked immunosorbent assay before abortion and at follow up

\begin{tabular}{lrr}
\hline & \multicolumn{2}{c}{ Serum IgG antibody titres } \\
\cline { 2 - 3 } Patient No & First sample* & Second samplet \\
\hline 1 & 32 & 128 \\
2 & 8 & 32 \\
3 & 8 & 32 \\
4 & 128 & 512 \\
5 & 32 & 32 \\
6 & 64 & 64 \\
7 & $<8$ & 2048 \\
8 & 8 & 512 \\
9 & 32 & 512 \\
10 & 32 & 256 \\
11 & 16 & 16 \\
12 & 8 & 8 \\
13 & 32 & 32 \\
14 & $\leqslant 8$ & $\leqslant 8$ \\
15 & $<8$ & $\leqslant 8$ \\
16 & 32 & 32 \\
17 & 128 & 128 \\
18 & 32 & 32 \\
19 & 128 & 128 \\
20 & 64 & 64 \\
21 & $\leqslant 8$ & $\leqslant 8$ \\
\hline
\end{tabular}

* Sample collected before abortion

† Sample collected at follow up

\section{Discussion}

The existence of pathogenic micro-organisms in the cervix before therapeutic abortion is of importance, particularly because of the risk of ascending infection. The incidence of chlamydial infection of the cervix in women undergoing termination of pregnancy is between $6 \%$ and $13 \% .{ }^{9}$ In the present study $C$ trachomatis was isolated in $13.8 \%$ and $N$ gonorrhoeae in $2.8 \%$ of patients.

Most chlamydial infections are confined to the epithelial cells of the mucous membranes of the genital tract. The antigenic stimulus is minimal and the humoral antibody response poor. The use of a sensitive serodiagnostic test is, therefore, important. In the present study an ELISA, which has the same sensitivity and specificity as the single-antigen immunofluorescence test, ${ }^{48}$ was used to detect chlamydial IgG antibodies. Of the 21 patients harbouring $C$ trachomatis who were followed up, 17 $(81 \%)$ had detectable chlamydial IgG antibodies; of these, eight had an appreciable rise in antibody titre. All the six patients who were followed up and developed salpingitis after termination of pregnancy had chlamydial antibodies. These results agree with those obtained by the micro-immunofluorescence test. 1011

The study indicates that patients harbouring $C$ trachomatis in the cervix at termination of pregnancy are at high risk of developing postoperative infections and that $C$ trachomatis is a major aetiological agent in salpingitis occurring after legal abortion. Routine screening for $C$ trachomatis in the cervix before surgery is thus essential. Although only the chlamydia-positive patients were followed up in this study, all patients will be examined thoroughly before and after therapeutic abortion in future studies.

\section{References}

1. Mårdh P-A, Helin I, Bobeck S, Laurin J, Nilsson $\mathrm{T}$ Colonisation of pregnant and puerperal women and neonates with Chlamydia trachomatis. Br J Vener Dis 1980; 56:96-100.

2. Mårdh P-A, Ripa T, Svensson L, Weström L. Chlamydia trachomatis infection in patients with acute salpingitis. NEngl J Med 1977; 296: 1377-9.

3. Punnonen R, Terho P, Nikkanen V, Meurman O. Chlamydial serology in infertile women by immunofluorescence. Fertil Steril 1979; 31:656-9.

4. Vik ISS, Skaug K, Qvigstad E, Ulstrup JC, Jerve F. Isolation and serological diagnosis of Chlamydia trachomatis in acute salpingitis. Tidsskr Nor Laegeforen (in press).

5. Westrom L. Effect of acute pelvic inflammatory disease on fertility. Am J Obstet Gynecol 1975; 121:707-13.

6. Jerve F, Fylling P. Therapeutic abortion. Acta Obstet Gynecol Scand 1978; 57:237-40.

7. Ripa T, Mårdh P-A. New simplified culture technique for Chlamydia trachomatis. In: Hobson D, Holmes KK, eds. Nongonococcal Urethritis and Related Infections. Washington DC American Society for Microbiology 1977;323-7.

8. Skaug K, Vik ISS, Qvigstad E, Ulstrup JC, Jerve $F$ Chlamydial serum IgG antibodies in patients with acute salpingitis measured by an enzyme-linked immunosorben assay. Acta Pathol Microbiol Scand (C) (in press).

9. Schachter J. Chlamydial infections. N Engl J Med 1978; 298:540-9.

10. Treharne JD, Dines RJ, Darougar S. Serological responses to chlamydial ocular and genital infections in the United Kingdom and Middle East. In: Hobson D. Holmes KK, eds. Non gonococcal Urethritis and Related Infections. Washington DC: American Society for Microbiology, 1977:249-58.

11. Wang S-P, Grayston JT, Kuo C-C, Alexander ER, Holmes KK. Serodiagnosis of Chlamydia trachomatis infection with the micro-immunofluorescence test. In: Hobson D, Holmes KK eds. Non-gonococcal Urethritis and Related Infections. Washington DC: American Society for Microbiology, 1977: 237-48. 